University of Nebraska - Lincoln

DigitalCommons@University of Nebraska - Lincoln

Faculty Publications, Department of Psychology

Psychology, Department of

2010

\title{
Prenatal Tobacco Exposure: Developmental Outcomes in the Neonatal Period
}

\author{
Kimberly Andrews Espy \\ University of Nebraska, kespy2@unl.edu \\ Hua Fang \\ University of Nebraska-Lincoln, hua.fang@umassmed.edu \\ Craig Johnson \\ University of Nebraska-Lincoln, cjohnson23@unl.edu \\ Christian Stopp \\ University of Nebraska-Lincoln, christianstopp@hotmail.com \\ Sandra A. Wiebe \\ University of Alberta, sandra.wiebe@ualberta.ca \\ See next page for additional authors
}

Follow this and additional works at: https://digitalcommons.unl.edu/psychfacpub

Part of the Psychiatry and Psychology Commons

Espy, Kimberly Andrews; Fang, Hua; Johnson, Craig; Stopp, Christian; Wiebe, Sandra A.; and Respass, Jennifer, "Prenatal Tobacco Exposure: Developmental Outcomes in the Neonatal Period" (2010). Faculty Publications, Department of Psychology. 502.

https://digitalcommons.unl.edu/psychfacpub/502

This Article is brought to you for free and open access by the Psychology, Department of at DigitalCommons@University of Nebraska - Lincoln. It has been accepted for inclusion in Faculty Publications, Department of Psychology by an authorized administrator of DigitalCommons@University of Nebraska - Lincoln. 
Authors

Kimberly Andrews Espy, Hua Fang, Craig Johnson, Christian Stopp, Sandra A. Wiebe, and Jennifer Respass 
Published in Developmental Psychology doi: 10.1037/a0020724 Copyright @ 2010 American Psychological Association. Used by permission. “This article may not exactly replicate the final version published in the APA journal. It is not the copy of record." http://www.apa.org/journals/dp/

This research was supported in part by National Institutes of Health Grants R01 DA014661, DA023653, DA015223, MH065668, and HD050309.

We gratefully acknowledge the participating families, hospital staff, and project personnel who made this work possible.

\title{
Prenatal Tobacco Exposure: Developmental Outcomes in the Neonatal Period
}

\author{
Kimberly Andrews Espy, ${ }^{1}$ Hua Fang, ${ }^{1}$ Craig Johnson, ${ }^{1}$ Christian Stopp, ${ }^{1}$ \\ Sandra A. Wiebe, ${ }^{2}$ and Jennifer Respass ${ }^{1}$ \\ 1. Department of Psychology and Office of Research, University of Nebraska-Lincoln \\ 2. Department of Psychology, University of Alberta, Edmonton, Alberta, Canada. \\ Corresponding author - Kimberly Andrews Espy, Office of Research, University of Nebraska-Lincoln, \\ 303 Canfield Administration Building, Lincoln, NE 68588-0443; email kespy2@unl.edu
}

\begin{abstract}
Smoking during pregnancy is a persistent public health problem that has been linked to later adverse outcomes. The neonatal period - the first month of life - carries substantial developmental change in regulatory skills and is the period when tobacco metabolites are cleared physiologically. Studies to date mostly have used cross-sectional designs that limit characterizing potential impacts of prenatal tobacco exposure on the development of key self-regulatory processes and cannot disentangle short-term withdrawal effects from residual exposure-related impacts. In this study, pregnant participants $(N=304)$ were recruited prospectively during pregnancy, and smoking was measured at multiple time points, with both self-report and biochemical measures. Neonatal attention, irritable reactivity, and stress dysregulation were examined longitudinally at three time points during the first month of life, and physical growth indices were measured at birth. Tobacco-exposed infants showed significantly poorer attention skills after birth, and the magnitude of the difference between exposed and nonexposed groups attenuated across the neonatal period. In contrast, exposure-related differences in irritable reactivity largely were not evident across the 1st month of life, differing marginally at 4 weeks of age only. Third-trimester smoking was associated with pervasive, deleterious, dose-response impacts on physical growth measured at birth, whereas nearly all smoking indicators throughout pregnancy predicted level and growth rates of early attention. The observed neonatal pattern is consistent with the neurobiology of tobacco on the developing nervous system and fits with developmental vulnerabilities observed later in life.
\end{abstract}

Keywords: prenatal tobacco exposure, self-regulation, longitudinal modeling

Approximately $20 \%$ of women acknowledge smoking during pregnancy in the United States (National Survey on Drug Use and Health; Office of Applied Studies, 2005), which results in at least 500,000 prenatally tobacco-exposed infants annually. Smoking during pregnancy is substantially more prevalent than prenatal use of alcohol or illicit drugs. For most women, smoking is a daily habit that, when pregnant, results in a regular dosing pattern to the fetus. As such, prenatal tobacco exposure carries broad risk for harm and potential morbidity (Koren, 1993; Slotkin, 1998b).

Tobacco contains a number of chemically active compounds. Nicotine appears to be the predominant contributor to the impact on growth and behavior of children exposed during pregnancy. Nicotine is a powerful vasoconstrictor that reduces the flow of available nutrients and oxygen to the developing fetus. Indeed, exposure-related reductions in birth weight have been reported in the literature for several decades. Besides birth weight, prenatal tobacco exposure is also associated with dose-dependent reductions in body length and head size (e.g., Hardy \& Mellits, 1972; Rantakallio, 1983;
Roza et al., 2007; Vik, Jacobsen, Vatten, \& Bakketeig, 1996). These exposure-related physical growth differences at birth usually resolve by the infant's first birthday (Conter, Cortinovis, Rogari, \& Riva, 1995; Day et al., 1992; Hardy \& Mellits, 1972). The physical growth deficits and the associated tobaccoexposure-related increase in perinatal complications both contribute to, but do not completely account for, a greater risk for attention-deficit/hyperactivity disorder (Nigg \& Breslau, 2007; Szatmari, Saigal, Rosenbaum, Campbell, \& King, 1990; Willoughby, Greenberg, Blair, Stifter, \& Family Life Investigative Group, 2007).

Although largely ignored for decades, nicotine is also a psychoactive compound that acts directly on the brain. Nicotine activates nicotinic acetylcholine receptors that are situated on dopamine neurons in the striatum and noradrenergic neurons in the locus coeruleus (Lichtensteiger et al., 1982) and are present as early as eight weeks gestation (Hagino \& Lee, 1985). In elegant preclinical work in nonhuman animals, prenatal tobacco exposure has been found to disrupt the timing of cholinergic synaptic activity during key developmen- 
tal periods, to alter receptor-mediated processes controlling cell replication and differentiation (Slotkin, 1998a), and to result in abnormal neuronal reactivity (Landmesser, 1994; Navarro, Seidler, Whitmore, \& Slotkin, 1988; Seidler, Levin, Lappi, \& Slotkin, 1992; Slotkin, Lappi, \& Seidler, 1995), including the disruption of developing dopaminergic circuits (Azam, Chen, \& Leslie, 2007). When administered prenatally, nicotine reduces postnatal dopaminergic activity in the ventral tegmental area, nucleus accumbens, and striatum (Chen, Parker, Matta, \& Sharp, 2005; Muneoka et al., 1997; Slotkin, 1998b), with a corresponding reduction in D2 dopamine receptors (S. A. Richardson \& Tizabi, 1994). Serotonergic systems are affected similarly, as prenatal tobacco exposure disrupts paroxetine binding to the 5-HT transporter (Levin \& Slotkin, 1998). These disruptions persist well after nicotine exposure has ceased (McFarland, Seidler, \& Slotkin, 1991), suggesting that prenatal nicotine exposure alters cell development programs in an irreversible manner (Slotkin, 1998b) that is not attributable solely to the hypoxic effects of nicotine on the central nervous system (Slotkin, Greer, Faust, Cho, \& Seidler, 1986).

Given the strong link between alterations of the dopaminergic and serotonergic brain systems and developmental psychopathology, it may not be surprising that many studies have linked prenatal tobacco exposure to externalizing behaviors in childhood (e.g., Day, Richardson, Goldschmidt, \& Cornelius, 2000; Wakschlag, Leventhal, Pine, Pickett, \& Carter, 2006) and to the clinical diagnoses of attention-deficit/hyperactivity disorder and oppositional defiant disorder (Huizink \& Mulder, 2006; Kotimaa et al., 2003; Orlebeke, Knol, \& Verhulst, 1999; Wakschlag, Pickett, Cook, Benowitz, \& Leventhal, 2002). Furthermore, self-reported prenatal smoking also has been associated with inattention, overactivity, and an impulsive response style at preschool and early school age (Day et al. 2000; Fried, Watkinson, \& Gray, 1992; Johnson, Vicary, Heist, \& Corneal, 2001; Leech, Richardson, Goldschmidt, \& Day, 1999), working memory and inhibition deficits in adolescents (Bennett et al., 2009; Fried \& Watkinson, 2001; Jacobsen, Slotkin, Westerveld, Mencl, \& Pugh, 2006), and negative emotionality in infants and young children (Brook, Brook, \& Whiteman, 2000; Fried \& Makin, 1987; Kelmanson, Erman, \& Litvina, 2002; Schuetze \& Eiden, 2007; Wakschlag \& Hans, 2002; Willoughby, Greenberg, Blair, Stifter, \& Family Life Investigative Group, 2007). Dose-response relations between prenatal tobacco exposure and such externalizing behaviors have been reported (e.g., Day et al., 2000; Linnet et al., 2003; Williams et al., 1998). Generally, the effect of exposure on these outcomes is robust but may be reduced in magnitude when adjusted for confounding environmental and genetic covariates (Linnet et al., 2003; Maughan, Taylor, Caspi, \& Moffitt, 2004; Rodriguez \& Bohlin, 2005; Thapar et al., 2003) or is eliminated in epidemiological within-family, sibling designs (e.g., D'Onofrio et al., 2007).

Results of studies conducted on newborns in the 1970s and 1980s with self-reported measures of smoking suggest exposure-related vulnerabilities in self-regulation. Saxton (1978) examined infant behavior shortly after birth in a small sample of infants born to women who smoked 15 or more cigarettes per day. Tobacco-exposed neonates showed reduced sensitivity to auditory stimuli, evidenced by greater auditory habituation and poorer orientation to auditory inanimate and animate stimuli. Other researchers (Fried, Watkinson, Dillon, \&
Dulberg, 1987; Picone, Allen, Olsen, \& Ferris, 1982) confirmed these findings and noted reductions in visual attention skills (S. W. Jacobson, 1984; G. A. Richardson, Day, \& Taylor, 1989; Streissguth, Sampson, Barr, Bookstein, \& Carmichael, 1994). Alterations in state behavior (i.e., increased irritability; Fried \& Makin, 1987; S. W. Jacobson, 1984; Stroud, Paster, Goodwin, et al., 2009), disrupted cry (Nugent, Lester, Greene, \& Wieczorek-Deering, 1996), and autonomic regulation (Picone et al., 1982) also have been associated with prenatal tobacco exposure, although not in all studies (G. A. Richardson et al., 1989). More recently, a handful of studies that included bioassay validation of exposure confirmed differences in withdrawal behaviors (heightened irritability, physiologic signs of stress) in the first few days of life (Godding et al., 2004; Law et al., 2003; Mansi et al., 2007) and hint at persistent differences later in the neonatal period in reactivity to handling (Stroud, Paster, Papandonatos, et al., 2009).

Despite its relative temporal brevity, there is substantial skill development in the neonatal period. Shortly after birth, the newborn works to independently achieve physiological stability and homeostasis, including regulation of arousal (Kopp, 1982; Riese, 1987). After homeostasis is achieved, the neonate regulates responsiveness to external stimuli through state modulation and directed orientation of attention (Bard, Coles, Platzman, \& Lynch, 2000; Emde \& Buchsbaum, 1989). Investigations that have focused on behavior shortly after birth likely do not fully capture the impacts of prenatal exposure on skill development across the period. From the perspective of exposure, the neonatal period begins with physiological clearing of nicotine and other tobacco compounds from maternal smoking late in pregnancy, where both exposure and withdrawal effects are evident shortly after birth. Later in the neonatal period, the persistent, residual impacts of exposure on neurobehavior can be observed without the confounding of short-term withdrawal behaviors. Furthermore, because behavioral manifestations of brain alterations may not be evident until the age at which the compromised area is called into action for skill execution (Goldman, 1974), in some cases long after the damage occurred, new insights can be gained by examining exposure-related outcome with repeated measurements. For the neonatal period, longitudinal designs permit characterization of how prenatal tobacco alters the developmental trajectory of regulatory skills and can help to disentangle short-term withdrawal from the more persistent, residual effects of exposure.

Indeed, results from a handful of studies hint at persistent differences later in the neonatal period. Fried and Makin (1987), for example, found greater impairment in tobaccoexposed infants in motor response at 30 days of age than at 9 days of age. More recently, Stroud, Paster, Papandonatos, et al. (2009) examined the impact of prenatal tobacco exposure on the regulatory behavior of 56 neonates at 10 to 27 days. Exposed neonates did not differ from their socioeconomic status (SES)- and alcohol exposure-matched peers in stress responses or muscle tone, but exposed infants exhibited a greater need for handling and scored lower on self-regulation items. In a large sample of White and Black infants, the amount of exposure indexed by maternal serum cotinine was related to differences in arousal and regulation at 5 weeks of age (Yolton et al., 2009). To date, no studies have leveraged longitudinal data to examine exposure-related differences across early development. 
The purpose of the present study, then, was to delineate the impact of prenatal tobacco exposure on the early development of emergent regulatory processes across the first month of life-the neonatal period-using a prospective, cohort design with self-reported and bioassay indices of exposure collected repeatedly during pregnancy. Using hierarchical growth modeling, we could then parse the effect of prenatal tobacco exposure into effects that influence the level of self-regulatory behavior at any given age and those that influence the rate of behavior change or development to better characterize the impact of exposure on the underlying developmental process. This modeling approach previously has been demonstrated to be useful. For example, Espy, Riese, and Francis (1997) observed that prenatal cocaine exposure differentially affected the developmental level and rate parameters. Building on extant findings, we hypothesized that tobacco-exposed neonates would show reduced self-regulatory skills after birth, manifested by poorer attention and orientation, increased irritability and greater stress dysregulation, as well as persistent exposure-related differences at 4 weeks of age. Because our study was motivated by a neural systems perspective to better characterize specific tobacco exposure effects, we were particularly interested in isolating the impact of tobacco exposure as much as possible and thus used strict participant selection procedures to minimize other exposures and influences. With these selection methods, we postulated that differences in self-regulatory behaviors would be related in a dose-response manner to the number of cigarettes smoked by the mother during pregnancy, indexed by self-report and bioassays at each trimester. We also examined exposure-related differences in physical growth at birth, as these indices have been shown to be important mediators in other behavioral teratologic studies (e.g., head circumference and prenatal cocaine exposure; Eyler, Behnke, Conlon, Woods, \& Wobie, 1998). Finally, exposure-related differences in the development of rudimentary self-regulatory processes were explored by evaluating differences in the rate of skill growth across the entire neonatal period.

\section{Method}

\section{Participants}

The sampling strategy was designed to compare two neonatal groups - tobacco exposed and nonexposed groups - and to minimize the influences of other exposures and sociodemographic differences. Consistent with this objective, study flyers were distributed over a 4.5-year period to all obstetric clinics in two sites in the Midwest: rural multicounty area in southern Illinois (surrounding the town of Carbondale) and a smallsized city (Lincoln, Nebraska). Interested pregnant women $(N=$ 915) called the laboratory and were screened for study eligibility with questions regarding due date, educational attainment, maternal race, smoking history and status, alcohol and illegal drug use, and (as a less intrusive proxy for income) Medicaid status. Women who reported at screening (a) illegal drug use or (b) alcohol use of four or more drinks on a single occasion (criterion for binge drinking; Centers for Disease Control, 2008) were eliminated as ineligible at screening and were not considered further for potential recruitment. Among screened women who reported no binge drinking and no illegal drug use, all women who reported smoking in the month around their last menstrual period or current active smoking on the screening were then recruited, enrolled, and preliminarily classified as tobacco exposed. Smoking at last menstrual period was chosen as the criterion to capture women who underdisclose smoking during very early pregnancy, when in fact, they quit smoking upon learning they were pregnant (which is well into the pregnancy period) and would therefore have been classified erroneously as nonexposed (England et al., 2007). Among screened women who reported no binge drinking, no illegal drug use, and no smoking at screening, those with lower educational attainment ( $<14$ years), majority race/ethnicity, and Medicaid status were overselected for subsequent recruitment to render the groups more comparable demographically given the known higher frequency of smoking in these groups $(N=387$ before data exclusions described below). Most participants (65\%) were enrolled prior to the 16th prenatal week, and all women were enrolled prior to the 28th prenatal week. Women's self-reported prenatal smoking behavior then was obtained prospectively at 16 weeks, 28 weeks, and delivery (hereinafter referred to as 40 weeks), with a modified timeline follow-back method (Sobell \& Sobell, 1992), where dates were used to cue recall and smoking was queried month by month.

Next, self-reported smoking behavior was examined for consistency with the initial group assignment. Where smoking status was consistent across the interviews and agreed with the last smoking date (if applicable), the exposure group assignment remained. For those who did not meet either of these criteria, the reported last smoking dates across the interviews were examined with regard to proximity of last menstrual period. If a participant was classified initially as nonexposed but reported last smoking dates falling within the window of pregnancy, then that participant was reclassified as tobacco exposed. Ten smokers reported no cigarette use during pregnancy that was inconsistent with their last menstrual period and reported last smoking dates. For these women, the missing average smoking amounts for the applicable trimesters were imputed with regression modeling (Little \& Rubin, 2002). The results of the biospecimen sampling were then examined to confirm smoking group assignment. We created plots of the cotinine levels, the nicotine by-product that was assayed by U.S. Drug Laboratories from samples collected from maternal urine at 16, 28, and 40 weeks of the pregnancy and from infant meconium shortly after birth (see Procedures for further details). Any nonsmoking woman with at least one urine cotinine value of $30 \mathrm{ng} / \mathrm{ml}$ or greater or whose infant had a meconium cotinine level of at least $30 \mathrm{ng} / \mathrm{g}$ was scrutinized further. Two mothers were reclassified as tobacco exposed who had at least one urine or infant meconium cotinine level greater than 100 , the cutoff value recommended by U.S. Drug Laboratories.

Because the purpose of this article was to examine the impact of prenatal tobacco exposure while minimizing confounding influences and other exposures, data from women/ neonates who met one of the four following criteria were excluded from analysis. First, although women who reported illegal drug use during screening were not recruited or enrolled, 53 women denied use at screening and then subsequently reported use of marijuana at a prenatal interview $(n=38)$ or their infant's meconium tested positive for marijuana at birth $(n=19)$. Second, one woman reported prescription antipsychotic medication use during pregnancy, which has known negative impacts on neonatal behavior. Because women who smoke are also more likely to drink, and to drink more in one sitting, than nonsmokers, we carefully measured 
alcohol use around the last menstrual period and during each month of pregnancy with the same structured, timeline follow-back methods as for smoking, querying about quantity, frequency, and variability. In the present sample, $83 \%$ of the women in the tobacco-exposed group reported drinking before pregnancy and prior to their last menstrual period compared with $61 \%$ percent of women in the nonexposed group, $\chi^{2}(1, N=304) \_18.51, p<.0001$. Furthermore, the average number of alcoholic drinks consumed per day during the first trimester of pregnancy differed between tobacco-exposed and nonexposed groups (shown in Table 1), as well as comparison of groups among drinkers only: for tobacco-exposed drinkers only, $M=0.18 ; S D=0.23$; for nonexposed drinkers only, $M=$ $0.04, S D=0.06 ; t(150)=-4.80, p<.0001$. The data also were excluded for eight women who reported at the first interview drinking one or more drinks per day on average (criteria for heavy drinking; Centers for Disease Control, 2008) for the first trimester. Only those with heavy drinking in the first trimester were excluded because, after removing the data from these eight women, we found that $85 \%$ of participants reported no alcohol use after the end of the first trimester. Furthermore, the amount and frequency of alcohol use in those who reported use after the first trimester was no more than one drink on one specifically identified occasion (e.g., a holiday or birthday) for all but six women (Trimester $2, M=0.028, S D=0.028$;
Trimester 3, $M=0.076, S D=0.082)$. Mean number of alcoholic drinks consumed per day reported for both the second and third trimesters for each exposure group (in Table 1) was very low, as well as when comparing groups among drinkers only (tobacco-exposed drinkers only: Trimester $2, M=0.004, S D=$ 0.009 ; Trimester $3, M=0.002, S D=0.009$; nonexposed drinkers only: Trimester 2, $M=0.007, S D=0.026$; Trimester 3, $M$ $=0.002, S D=0.010)$. Although our focus was on prenatal tobacco exposure while minimizing other exposures, we elected not to exclude the data from women who consumed any alcohol (even though in relatively low amounts in this sample) to conserve sample size and preserve generalizability because of the common comorbidity of smoking and alcohol use, particularly prior to pregnancy detection. Therefore, we included prenatal alcohol use during the first trimester as a potential covariate (see Procedures section below for further details). Finally, to minimize the well-known influence of gestational age on self-regulatory behavior (Korner, Brown, Dimiceli, \& Forrest, 1989; Riese, Wilson, \& Matheny, 1985), data from 10 infants born preterm (before 36 weeks) also were removed. Of the 10 removed, eight were tobacco exposed.

A total of 304 women and their infants met the criteria for inclusion, with 143 infants classified as tobacco exposed and 161 as nonexposed (138 women/infants from the rural Illinois site and 166 women/infants from the urban Nebraska site,

Table 1. Maternal Variables by Tobacco Exposure Group

\begin{tabular}{|c|c|c|c|c|c|c|c|c|}
\hline Maternal demographic, health, and perinatal variables & \multicolumn{2}{|c|}{$t$ test } & \multicolumn{3}{|c|}{ Tobacco exposed } & \multicolumn{3}{|c|}{ Nonexposed } \\
\hline Maternal age at delivery (years) & $2.08^{*}$ & $(302)$ & 25.3 & 5.0 & & 26.5 & 5.0 & \\
\hline Median monthly family income (\$) & & & 1,742 & & & 1,820 & & \\
\hline Gravida & -1.29 & $(302)$ & 1.77 & 2.21 & & 1.50 & 1.41 & \\
\hline Parity & 0.33 & $(302)$ & 1.04 & 1.33 & & 1.09 & 1.05 & \\
\hline Medicaid & & & & & 84 & & & 83 \\
\hline Married ** & & & & & 36 & & & 54 \\
\hline Placental abruption & & & & & 0.3 & & & 0.0 \\
\hline \multicolumn{9}{|l|}{ Delivery } \\
\hline Spontaneous vaginal & & & & & 41 & & & 54 \\
\hline Antidepressant medication & & & & & 12 & & & 9 \\
\hline Diabetes & & & & & 6 & & & 7 \\
\hline Hypertension/pre-eclampsia & & & & & 11 & & & 14 \\
\hline Infection & & & & & 11 & & & 11 \\
\hline Heart disease & & & & & 4 & & & 3 \\
\hline Thyroid disease & & & & & 1 & & & 4 \\
\hline WJ-III BIA overall IQ estimate & $2.88^{* *}$ & $(297)$ & 95.52 & 10.77 & & 99.23 & 12.29 & \\
\hline BSI General Severity Index $T$ score & -1.77 & $(300)$ & 57.04 & 8.39 & & 55.34 & 8.39 & \\
\hline CAARS Attention Deficit/Hyperactivity Disorder T score & -0.87 & $(300)$ & 46.74 & 8.26 & & 45.96 & 7.87 & \\
\hline \multicolumn{9}{|l|}{ Maternal prenatal drinking (drinks/day) } \\
\hline Trimester 1 average & $-6.77^{* * *}$ & $(300)$ & 0.127 & 0.206 & & 0.015 & 0.038 & \\
\hline Trimester 2 average & $-2.15^{*}$ & $(301)$ & 0.003 & 0.008 & & 0.001 & 0.006 & \\
\hline
\end{tabular}

WJ-III BIA = Woodcock-Johnson III Brief Intellectual Ability Assessment (Woodcock, Johnson, \& Mathers, 2001); BSI = Brief Symptom Inventory (Derogatis, 1975); CAARS = Conners Adult ADHD Rating Scale, Short (Conners, Erhardt, \& Sparrow, 1998).

${ }^{*} p<.05 ;{ }^{* *} p<.01 ;{ }^{* * *} p<.001$. 
where exposure groups by site were comparable). ${ }^{1}$ The sample included 235 White, non-Hispanic women (77.3\%); 15 White, Hispanic women (4.9\%); 40 African American women (13.2\%); and 9 Native American women $(3.0 \%)$. On average, mothers completed 13.5 years of education $(S D=1.7)$. Although language spoken in the home was not collected, all women were proficient English speakers. Women in the tobacco-exposed and nonexposed groups were comparable in the percentage receiving Medicaid assistance but differed in the proportion married at enrollment, age at delivery, and educational attainment. There were no differences between exposure groups in the proportion of female infants, infant gestational age at birth, or infants who were of White, non-Hispanic race/ethnicity. Tables 1 and 3 depict the respective descriptive statistics for women and neonate participants by exposure group.

\section{Procedures}

Tobacco exposure. Women were interviewed with the structured, timeline follow-back method in a private room by trained researchers (the research technicians who conducted interviews were not the same as those who conducted neonatal evaluations to ensure blind assessment) at 16, 28, and 40 weeks (just after delivery) to gain information on prenatal tobacco and alcohol use. The comprehensive interview included background and other health-related questions, as well as queries about quantity, frequency, and variability information regarding tobacco and alcohol use by month. These month-bymonth values were averaged into trimester indices. At each session, women provided a urine sample in a sterile cup, where $100 \%$ of women provided samples at the 16 -week interview, $99 \%$ at 28 weeks, and $96 \%$ at delivery, as occasionally women had difficulty providing a sufficiently clean sample for cotinine assay after delivery. After the neonate was born, nurses collected meconium samples until a total weight of 25 $\mathrm{g}$ was obtained. However, some neonates voided meconium in utero or during delivery, preventing collection of an adequate volume of meconium for later assay. A total of 255 neonate meconium cotinine results were available for analysis.

Once nicotine is absorbed by the mother during smoking, it is metabolized into cotinine and is detectable in the urine up to several days after the termination of smoking. To measure cotinine level in participants' urine samples, we used the DRI Cotinine Assay from U.S. Drug Laboratories. The DRI cotinine assay is a liquid, ready-to-use homogeneous enzyme immunoassay based on competition between cotinine labeled with glucose-6-phosphate dehydrogenase enzyme and free cotinine in the sample for a fixed amount of cotinine-specific antibody binding sites. The glucose- 6-phosphate dehydrogenase enzyme activity is determined spectrophotometrically at 340 $\mathrm{nm}$ by measuring its ability to convert nicotinamide adenine dinucleotide (NAD) to NAD-hydrogenase. This assay utilizes DRI cotinine calibrators and controls, which are prepared by spiking negative human urine with a known quantity of cotinine. The cotinine concentration is obtained by running a standard curve with the appropriate calibrators and by quantitat- ing samples off the standard curve.

The tobacco exposure information is provided in Table 2. A total of $43 \%$ of the tobacco-exposed group reported smoking 10 or more cigarettes per day on average before pregnancy and prior to the last menstrual period. The average number of cigarettes smoked during each trimester and at the 16-, 28-, and 40 -week interviews was substantially less, between three and six cigarettes per day. Although $39 \%$ of the women reported that they no longer smoked by the end of the first trimester and $50 \%$ reported no longer smoking by the end of the second trimester, the average maternal urinary cotinine values for the tobacco-exposed group at 28 weeks did not differ from those collected at 16 weeks: 16 weeks, $M=331 \mathrm{ng} / \mathrm{mL}$, $S D=537 ; 28$ weeks, $M=353 \mathrm{ng} / \mathrm{mL}, S D=564, t(87)=-0.72$, $p>.45$. The lowest average cotinine value for the tobacco-exposed group was at delivery. The average cotinine values for the nonexposed group were less than $15 \mathrm{ng} / \mathrm{ml}$ across all occasions. As expected, the mean cotinine values in maternal urine and neonate meconium differed between the tobacco-exposed and nonexposed groups at all time points (all $p s<.01$ ). Table 4 provides intercorrelations of the self-reported smoking behavior variables and the cotinine assay results at all time points.

Neonate urine samples were collected from soft cloths inserted into the diaper at the 2- and 4-week sessions to assess environmental tobacco smoke exposure. U.S. Drug Laboratories conducted the DRI cotinine assay on these postnatal urine samples. Tobacco-exposed and nonexposed group mean 2and 4-week neonate urinary cotinine levels did not differ and are shown in Table 2.

Neonatal assessment. Although the state ratings, auditory and visual stimuli, and reflex maneuvers are similar among most neonatal instruments as a result of the limited behavioral repertoire of the young neonate, we chose the Neonatal Temperament Assessment (NTA) to measure emergent regulatory skills because of its unique modules that include graded stressors designed to probe the regulatory system and known psychometric properties. Psychometric properties of the NTA have been reported as good (Riese, 1982), where interrater reliability and internal consistency range from 0.85 to 0.97 and 0.72 to 0.86 , respectively (Riese, 1983). We calculated interrater reliabilities from coscoring $4 \%$ of all assessments administered, with obtained reliabilities ranging from .89 to .99 . With regard to predictive validity, Riese and colleagues (Matheny, Riese, \& Wilson, 1985; Riese, 1995; Riese, Wilson, \& Matheny, 1985) have shown that neonatal temperament is related to later maternal reports and direct laboratory behavioral observations of infant temperament at 6 months, 9 months, and 2 years. In these studies, those who were more irritable perinatally were rated as more upset, more variably active, less attentive to stimuli, and less responsive (Riese, 1987).

Research technicians administered the standardized NTA, which was designed to evaluate individual differences in early regulatory behaviors three times in the neonatal period, at 0.2 weeks (about two days) after birth in the hospital, at 2 weeks of age in the university laboratory and at 4 weeks of age in the participant's home. Following the work

1. Recruitment was balanced across sites, as the interaction of site by exposure group was not significant for nearly all demographic, maternal, and perinatal variables. The only exception was that there were more nonsmoking women enrolled at the Illinois site who had private insurance, $X^{2}(1, N=304)=7.97, p<.01$. A total of 23 nonexposed-Illinois, 4 nonexposed-Nebraska, 11 tobacco-exposed-Illinois, and 12 tobacco-exposedNebraska participants had private insurance. 
Table 2. Maternal Smoking and Infant Exposure Variables by Tobacco Exposure Group

\begin{tabular}{|c|c|c|c|c|c|c|c|}
\hline \multirow[b]{2}{*}{ Tobacco-related variable } & \multicolumn{2}{|c|}{$t$ test } & \multicolumn{3}{|c|}{ Tobacco exposed } & \multicolumn{2}{|c|}{ Nonexposed } \\
\hline & $t$ & $(d f)$ & $M$ & $S D$ & $\%(n)$ & $M$ & $S D$ \\
\hline \multicolumn{8}{|c|}{ Maternal self-reported prenatal smoking (no. of cigarettes/day) } \\
\hline At 16-week interview & & & 3.62 & 6.21 & & & \\
\hline Trimester 2 & & & 3.84 & 6.17 & & & \\
\hline At 28-week interview & & & 3.80 & 6.31 & & & \\
\hline \multicolumn{8}{|l|}{ Cotinine level } \\
\hline 16-week maternal urine $(\mathrm{ng} / \mathrm{ml})$ & $-6.27^{* * *}$ & (195) & 330.90 & 536.60 & & 5.64 & 13.78 \\
\hline 28-week maternal urine $(\mathrm{ng} / \mathrm{ml})$ & $-7.71^{* * *}$ & $(300)$ & 352.89 & 563.65 & & 10.40 & 18.22 \\
\hline At delivery maternal urine $(\mathrm{ng} / \mathrm{ml})$ & $-4.49^{* * *}$ & (291) & 83.85 & 198.27 & & 12.06 & 19.12 \\
\hline At delivery neonate meconium (ng/g) & $-2.63^{* * *}$ & $(249)$ & 192.74 & 856.51 & & 0.39 & 3.43 \\
\hline 2-week infant urine cotinine $(\mathrm{ng} / \mathrm{ml})$ & -1.55 & (259) & 21.67 & 32.14 & & 16.32 & 23.27 \\
\hline
\end{tabular}

QUIT = quit smoking in Trimester 1 or 2 and remained smoke-free throughout delivery

PERSIST $=$ smoked throughout pregnancy in all three trimesters

${ }^{*} p<.05 ;{ }^{* *} p<.01 ;{ }^{* * *} p<.001$

of Riese (1982, 1986), research technicians were taught initially in handling and working with neonates and then were trained in how to administer the NTA items. Before completion of training, each research technician achieved an initial reliability of greater than $90 \%$ with at least 10 neonates (determined by double coding of assessments). Random cases (10\%) were selected for double coding throughout the study to ensure that ongoing reliability in administration remained above $90 \%$. The NTA author conducted the extended, initial training session for study staff at the beginning of the study and one additional follow-up session during the study. To maintain blindness to tobacco-exposure group membership, we designed the study so that examiners who conducted the interviews with the mothers were different than those who conducted the NTA assessments with the neonates. However, it was impossible to keep the examiners uninformed of tobacco use in the home at the 4-week assessment that was conducted in the home, although tobacco use in the home is not an indicator of prenatal exposure group membership per se. Neonates averaged 0.2 weeks of age $(S D=0.14)$ at the birth assessment, 2.24 weeks $(S D=0.40)$ at the 2-week assessment, and 4.22 weeks $(S D=0.47)$ at the 4 -week assessment. Gestational ages at birth were corrected such that the 2- and 4-week assessments were scheduled to equate conceptional age. The age range window was \pm 1 week at the 2 -week assessment and \pm 1.5 weeks for 4 -week assessment. There were no age differences at any assessment between tobacco-exposed and nonexposed groups (all $p \mathrm{~s}>.05$ ).

Table 3. Infant Variables and Physical Growth Parameter Outcomes by Tobacco Exposure Group

\begin{tabular}{|c|c|c|c|c|c|c|c|c|}
\hline \multirow[b]{2}{*}{ Neonate variable } & \multicolumn{2}{|c|}{$t$ test } & \multicolumn{3}{|c|}{ Tobacco exposed } & \multicolumn{3}{|c|}{ Nonexposed } \\
\hline & $t$ & $(d f)$ & $M$ & $S D$ & $\%$ & $M$ & $S D$ & $\%$ \\
\hline Length of hospitalization (days) & -0.53 & (301) & 2.3 & 1.1 & & 2.2 & 1.2 & \\
\hline 5-min Apgar & 0.66 & (301) & 8.78 & 0.73 & & 8.83 & 0.57 & \\
\hline Birth weight (g) & -0.15 & (301) & 3,428 & 438 & & 3,420 & 448 & \\
\hline Head circumference $(\mathrm{cm})$ & 0.70 & (299) & 34.2 & 1.5 & & 34.3 & 2.1 & \\
\hline Length (cm) & 0.16 & (299) & 50.7 & 2.2 & & 50.7 & 2.6 & \\
\hline \multicolumn{9}{|l|}{ Race/ethnicity } \\
\hline White & & & & & 63 & & & 58 \\
\hline African American & & & & & 22 & & & 26 \\
\hline Hispanic & & & & & 11 & & & 12 \\
\hline Asian & & & & & 1 & & & 1 \\
\hline Native American & & & & & 1 & & & 2 \\
\hline
\end{tabular}

${ }^{*} p<.05 ;{ }^{* *} p<.01 ; * * * p<.001$. 
Table 4. Intercorrelations of Self-Reported Smoking and Maternal Urine/Infant Meconium Cotinine Value

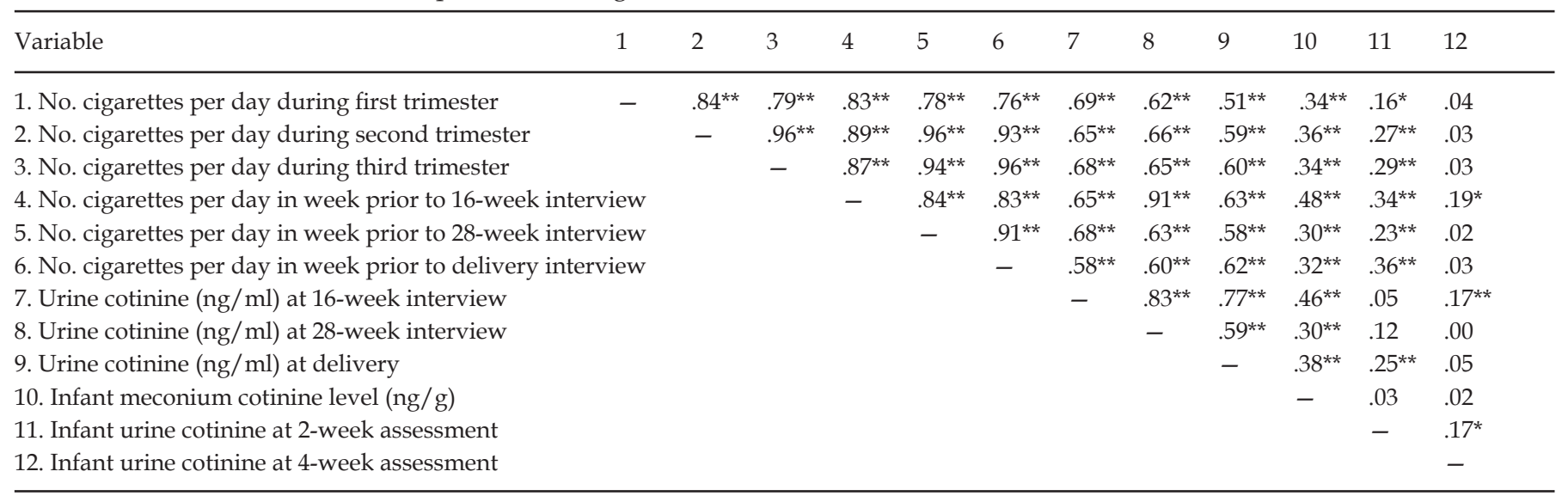

${ }^{*} p<.05 ;{ }^{* *} p<.001$

The NTA is designed to be conducted from the initiation of feeding during the interval prior to the next feeding (approximately 3 to $4 \mathrm{hr}$, depending on feeding schedule), thereby utilizing the neonate's natural sleep, wake, alertness, and irritability patterns. More details concerning administration procedures are provided in Riese (1982, 1986, 1987). Briefly, neonatal temperament and behavior in response to feeding, routine handling, auditory and visual stimulation, stressors (a cold disc applied to the neonate's thigh, aversive stimuli that elicit reflexes), and interventions (pacifier, examiner talking, swaddling, picking up) are recorded, including the degree of motor activity, and the level and quality of alertness and orientation. The states in which to present different stimuli to the neonates are specified in Riese (1987) and were followed accordingly, with the use of traditional management methods to facilitate acceptable state for each item and module. Assessments were conducted approximately $45 \mathrm{~min}$ after last feeding in a quiet, dimly lit area in the room. The examiner first recorded the neonate's length and weight and rated the neonate's state on a 6-point scale $(1=$ quiet sleep; 2 = active sleep; 3 = drowsy; 4 = alert inactivity; $5=$ waking activity; 6 = crying). Next, we administered four modules of the NTA: attention/ orientation, cold disc stressor, pacifier withdrawal, and soothing maneuvers.

The attention/orientation module was administered when the neonate was awake and not irritable. During administration, the neonate's responses to auditory and visual stimuli and to reflex maneuvers were scored, and summary ratings of responsiveness and neonate's reinforcement value were recorded. Auditory stimuli, such as a bell, a rattle, or the examiner's voice, were presented at the right and left sides of the neonate three times each for each stimulus, for a total of 18 trials. Each auditory trial was scored on a 4-point scale $(1=$ no orienting response; $4=$ a strong orienting response with eyes searching and head turning toward the sound). For visual stimuli (e.g., bulls-eye, examiner's face), the stimulus was positioned first at the center of the visual field, then moved around the neonate's head to the right or to the left at a $90^{\circ}$ angle, back to the center, around the other side at a $90^{\circ}$ angle, and then back to the center. Each visual item first moved to the right or to the left twice, for a total of four trials with each item. Visual items were scored on a 4 -point scale $(1=$ no following response; $4=$ sustained fixation and following with eyes and head). Ocular reflexes, optic and acoustic blinks, and rotation were adminis- tered, as well as elicitation of rooting, sucking, withdrawal to toothpick prick, and Moro reflexes. Although these items were scored on a 3- or 4-point scale, such reflex testing typically results in little variability in healthy full-term neonates. Therefore, in response to these maneuvers, the latency to cry was recorded and the degree of irritability was rated on a 5-point scale $(1=$ not irritable; 5 = highly irritable). Finally, the examiner made summary ratings of the neonate's general appearance and alertness $(1=$ poor; $5=$ excellent $)$, cuddliness $(1=r e-$ sists and/or thrashes and/or stiffens; $5=$ always molds, relaxes and clings), responsiveness to the different stimuli $(1=$ not irritable; $5=$ highly irritable $)$, consolability $(1=$ never irritable $5=$ unconsolable), reinforcement value of the neonate to the examiner ( 1 = glad to be finished; 5 = fun to have at home), and predominant state throughout the module.

The cold disc stressor module was administered when the neonate was quiescent and not irritable. This module consisted of five trials in which a metal disc cooled by immersion in ice water was held against the quiescent neonate's thigh for $5 \mathrm{~s}$. The neonate's latency to irritability (in seconds), rated irritability during and after presentation of the stimulus, duration of soothing if required (in seconds), and total latency to soothe (in seconds) were recorded. Trials were presented at least $60 \mathrm{~s}$ apart, and the intertrial interval was lengthened if necessary to soothe the neonate. If the neonate was not soothed after 3 min, subsequent trials were discontinued. An overall summary rating $(1=$ not irritable to cold disc; $6=$ unconsolable $)$ also was scored at the conclusion of the module.

The pacifier withdrawal module was administered when the neonate reached a moderate level of irritability, with fussiness and intermittent cry vocalizations. After the examiner noted the degree of irritability, a pacifier was given to the crying neonate. The latencies to suck and to console (in seconds) were recorded. After $30 \mathrm{~s}$, the examiner removed the pacifier while the neonate was still sucking and again recorded the latency to cry, behavioral state, and posttrial irritability level (1 $=$ not irritable, or no soothing needed; $5=$ could not console with pacifier in $3 \mathrm{~min}$ ). Up to five pacifier withdrawal trials were administered. Trials were terminated if the neonate did not become irritable after $3 \mathrm{~min}$. An overall summary rating $(1=$ not irritable, or no soothing needed to pacifier withdrawal; $5=$ could not console with pacifier in $3 \mathrm{~min}$ on any trial) was made at the conclusion of the module. 
The soothing maneuvers module also was administered when the neonate was at a moderate level of irritability. Trials consisted of graded items designed to foster soothing and were presented in the following order: soothingly talking to the neonate, soothing talking plus patting the neonate's stomach, putting the neonate in the prone position, lifting the neonate to the shoulder, swaddling the neonate, and cradling the swaddled neonate horizontally. Before each trial, the examiner rated the degree of irritability, whereas after each trial, the examiner rated degree of soothability. At the end of the module, the examiner made an overall summary rating $(1=$ no soothing needed; $5=$ not soothed by any technique). When the NTA was concluded, the examiner scored the neonate's final behavior state.

Other potential influences on neonatal self-regulation. Smoking during pregnancy is related to maternal and neonatal risk factors - such as lower maternal education, depression, psychopathology symptoms (e.g., Baghurst, Tong, Woodward, \& McMichael, 1992; Schuetze \& Eiden, 2006; Wakschlag, Pickett, et al., 2002), maternal health, and perinatal complications - which are associated with adverse developmental outcomes independent of exposure (e.g., Eyler \& Behnke, 1999; Schuetze \& Eiden, 2007; Schuetze, Eiden, \& Dombkowski, 2006). During all study sessions, women completed questionnaires and study instruments, including a brief psychiatric symptom screening (Brief Symptom Inventory; Derogatis, 1975), the Conners Adult ADHD Rating Scale: Short (Conners, Erhardt, \& Sparrow, 1998), and the Woodcock-Johnson Brief Intellectual Ability assessment (Woodcock, McGrew \& Mather, 2001). Standardized scores derived from instrument normative tables were used in the analyses.

\section{Analysis}

Creating factor scores. Unlike in previous studies with the NTA, we elected to pool and reduce the dependent variables into meaningful constructs to enhance reliability using princi- pal axis factor analysis with oblique (promax) rotation. Those items (largely the reflex items) with communalities of less than 0.35 were eliminated because of unreliability (Gorsuch, 1983). As recommended by Gorsuch (1983), we examined eigenvalues $(>1)$, scree plots, and the percentage of variance explained $(>10 \%)$ to select the number of factors to retain. Results indicated that a three-factor solution best fit the data. The factor pattern matrix is shown in Table 5. Factor 1 was labeled Irritable Reactivity, as it was composed largely of the neonate's irritable reaction to the auditory and visual stimuli and to routine handling as a part of reflex elicitation and maneuvers. Factor 2 , composed of the neonate's orientation and attention to auditory and visual stimuli, was labeled Attention. Finally, the items that involved reactions to the cold disc, pacifier, and soothing maneuvers, as well as behavior prior to the next feeding, loaded on the third factor, labeled Stressor Dysregulation. The average factor intercorrelations were as follows: for Irritable Reactivity and Attention, $r=-.20$; for Irritable Reactivity and Stress Dysregulation, $r=.46$; and for Attention and Stress Dysregulation, $r=.11$. The three computed factor scores for each participant at each time point were used as the dependent variables, and the means and standard errors of each factor by exposure group are plotted in Figure 1a.

Developing the baseline growth model. To evaluate the impact of prenatal tobacco exposure on the development of neonatal regulation, we used hierarchical linear models to model change across the three time points, with a separate model for each regulatory factor. Hierarchical linear modeling takes advantage of the increased reliability of change assessments when data are collected at more than two time points to characterize developmental processes and deviations. The first analytic step was to determine the baseline growth model derived from the unconditional model that included only a person-level variance term (i.e., a random intercept). Before any modifications were made to the structure of either age or the variance components in the model, gestational age was introduced as a covariate in each model because of its known im-

Table 5. Neonatal Temperament Assessment Factor Structure and Observed Interfactor Correlations

\begin{tabular}{|c|c|c|c|}
\hline Neonatal temperament assessment item & \multicolumn{3}{|c|}{ Factor loading } \\
\hline Irritability before feeding & 0.40 & 0.06 & 0.81 \\
\hline Irritability to visual stimuli & 0.88 & -0.12 & 0.43 \\
\hline Irritability to auditory stimuli & 0.80 & -0.19 & 0.37 \\
\hline Irritability to handling & 0.89 & -0.11 & 0.44 \\
\hline Soothability after reflex elicitation & 0.85 & -0.11 & 0.40 \\
\hline Mean visual following - bull's-eye & -0.18 & 0.67 & 0.05 \\
\hline Mean auditory orienting - rattle & -0.07 & 0.87 & 0.10 \\
\hline Mean auditory orienting - bell & -0.04 & 0.87 & 0.10 \\
\hline Mean auditory orienting - voice & -0.14 & 0.90 & 0.12 \\
\hline Mean visual following - face and voice & -0.09 & 0.61 & 0.10 \\
\hline Rated reinforcement value & -0.67 & 0.34 & -0.32 \\
\hline
\end{tabular}

Significant factor loadings (above 0.60 or below -0.60 ) are presented in boldface. 

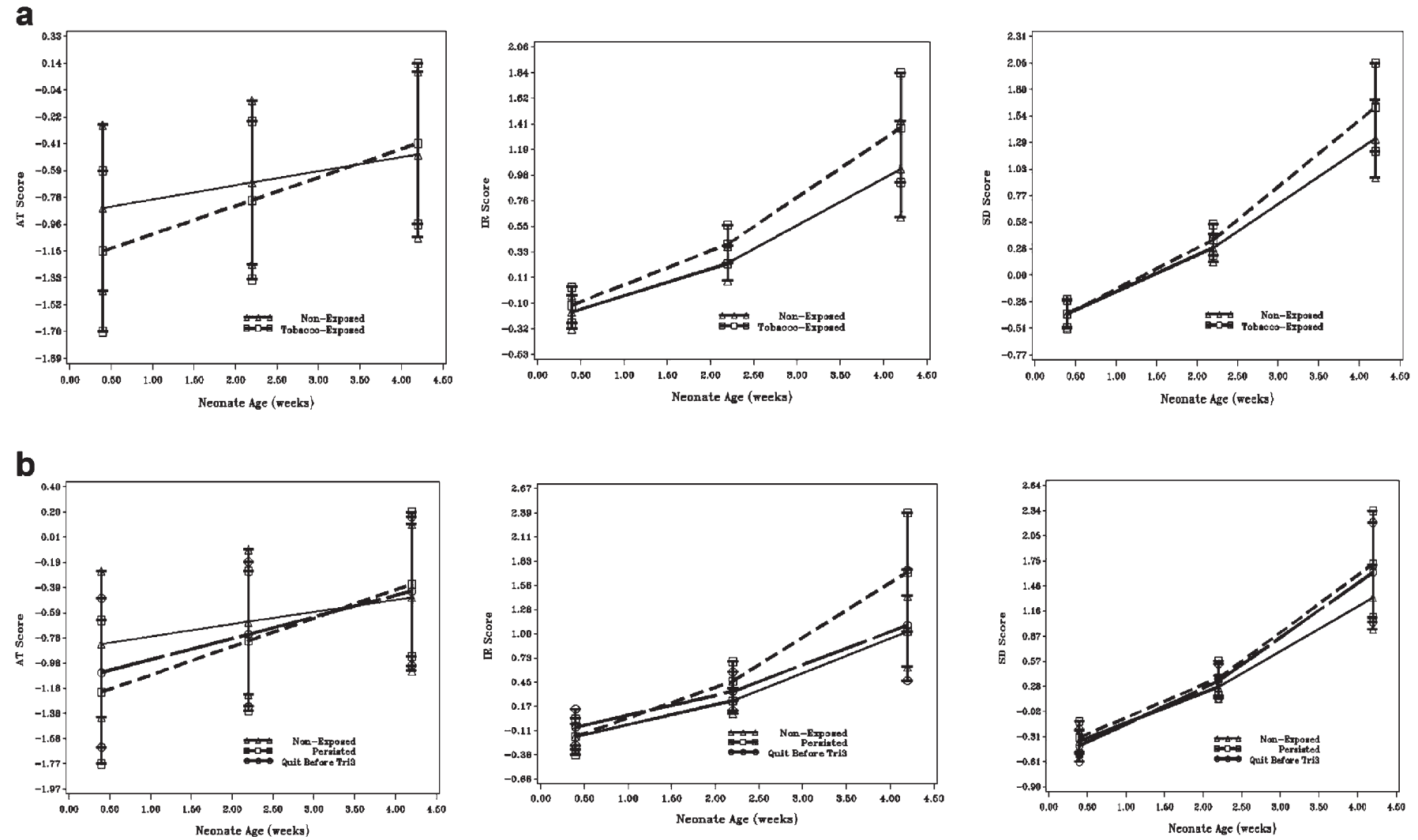

Figure 1. Growth in attention, irritable reactivity, and stress dysregulation factor scores in neonates. (a) Tobacco-exposed and nonexposed neonates; (b) tobacco-exposed neonates whose mothers quit in the first or second trimester, those who persisted, and nonexposed neonates.

pact on neonatal neurobehavior (e.g., Korner, Brown, Dimiceli, \& Forrest, 1989; Riese et al., 1985). Gestational age was a significant predictor of each of the dependent variables in the linear growth models of age: for Attention, $t(300) \ldots 3.61, p_{-}$ .001 ; for Irritable Reactivity, $t(304)=2.72, p<.01$; and for Stress Dysregulation, $t(304)=2.26, p<.03$. Therefore, we retained this variable as a covariate in all models. Recruitment site was included in all models as a covariate to control for any spurious site-specific variance.

Visual inspection of spaghetti plots of individual factor scores across the three observations suggested that modeling age as a quadratic process might be most appropriate to describe growth in the Irritable Reactivity and Stress Dysregulation constructs. Although Attention growth appeared linear, fit of the quadratic term was evaluated for consistency. In these analyses, age was centered at 0.2 weeks, and each of the three factor scores was then fitted as functions of linear and quadratic (centered) age. The coefficient for the quadratic term did not differ from zero for Attention, $t(676)=$ $-0.17, p>.86$, but differed from zero for both Irritable Reactivity, $t(675)=-6.49, p<.0001$, and Stress Dysregulation, $t(683)=-7.64, p<.0001$.

Next, we considered deviations in modeling the personlevel covariance structure, where the coefficient of the age term was allowed to vary in each of the models. For the linear model of Attention, model fit comparisons indicated that the random-intercept-only model was preferred (Akaike information criterion [AIC] of 2,423.1 vs. 2,424.4 for the random inter- cept-and-slope model; Bayesian information criterion [BIC] of $2,430.5$ vs. $2,439.3$ for the random intercept-and-slope model). For Irritable Reactivity, the model allowing for both random intercept and slope terms improved model fit when both AIC values $(2,404.8$ vs. 2,435.2 for the random-intercept-only model) and BIC values (2,412.2 vs. $2,442.6)$ were considered. A fairly wide range of quadratic trends were also exhibited in the individual plots for Irritable Reactivity. Thus, models were fitted where the (centered) age and quadratic age terms were allowed to vary across neonates in separate models. Like Stress Dysregulation, the growth model that included random intercept and slope terms significantly improved model fit over the random-intercept-only model when AIC values alone were considered (2,260.7 vs. 2,267.7 for the random intercept only) but not when considering BIC (2,275.6 vs. 2,275.2). The final baseline model for Attention, then, was linear in age, with only the intercept as a random coefficient, whereas for Irritable Reactivity and Stress Dysregulation, linear and quadratic changes in age were modeled, with only the intercepts allowed to vary randomly among neonates.

Modeling the impact of exposure. Exposure-related predictors were considered in separate models and included exposure group (tobacco exposed vs. nonexposed); exposure-cessation group: QUIT (stopped smoking during pregnancy during the first or second trimester and remained quit throughout the third trimester) versus PERSIST (smoked throughout pregnancy); average self-reported smoking for each trimester (cigarettes/day); average self-reported smoking 
Table 6. Exposure-Related Predictors and Impact on the Neonatal Physical Growth Measured at Birth

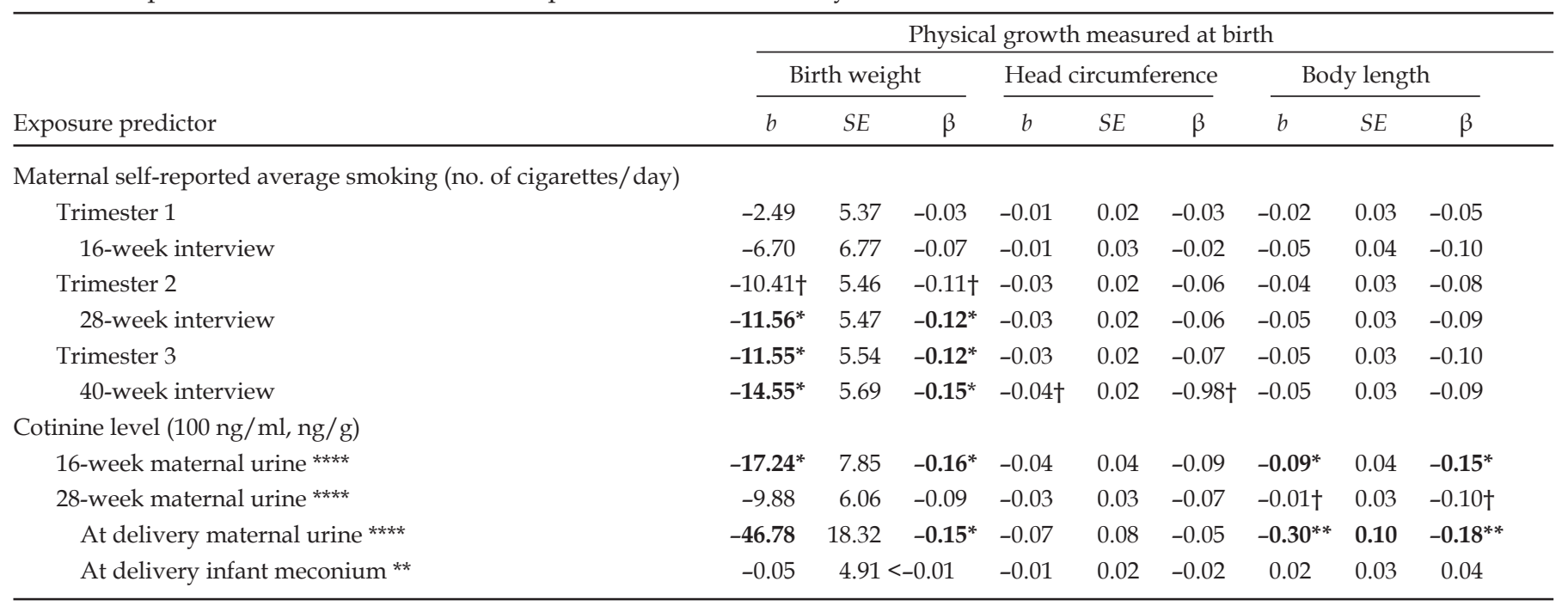

$b=$ unstandardized beta weight; $S E=$ standard error; $\beta=$ standardized beta weight.

$\dagger p<.10 ;{ }^{*} p<.05 ; * * \quad p<.01$

at the 16-, 28-, and 40-week interviews (cigarettes/day); maternal urinary cotinine level at the 16-, 28-, or 40-week interviews (scaled in units of $100 \mathrm{ng} / \mathrm{mL}$ ); and neonate meconium cotinine level (scaled in units of $100 \mathrm{ng} / \mathrm{g}$ ). To characterize the impact of exposure on physical growth, we conducted $t$ tests where the exposure variable was categorical and regressions were used for continuously distributed exposure variables. For the hierarchical growth models, we developed conditional models to test the hypotheses including the effect of the exposure-related predictor on both the intercept and growth parameters. We conducted the analyses, centering at $0.2,2$, and 4 weeks, respectively, in order to characterize the relation to neonatal behavior at each time point. We entered each exposure-independent variable as a predictor of the pattern of growth (intercept, linear change, quadratic acceleration) and then used a backwards trimming procedure to select the best fitting conditional model, deleting those when not significant for the higher growth term and then working progressively backwards through the growth terms. We scaled the continuous predictors so that the estimated parameter represented the incremental change in the dependent variable that was associated with each additional cigarette smoked or each additional 100 cotinine units at that interview.

Selection of covariates. We considered a range of covariates for inclusion: marital status, maternal education, family income, mother's age at delivery, average number of alcoholic drinks per day during the first trimester, Medicaid status, neonate sex, neonate and mother's race/ethnicity (White vs. non-White), neonate environmental tobacco exposure (as measured by cotinine in neonate urine collected at the 2- and the 4-week assessments), maternal prescription medication use (antidepressant, pain, or asthma medication, each coded as $0=$ absent; 1 = present), gravida, parity, weight gain, mother health and delivery variables (diabetes, heart disease, placental abruption, thyroid, anemia, hypertension/pre-eclampsia, infection, delivery type [vaginal vs. cesarean/other] with the same 0,1 coding), Brief Symptom Inventory summary index, Attention Deficit/Hyperactivity Disorder index of the Conners Adult ADHD Rating Scale: Short, and the Woodcock-
Johnson Brief Intellectual Ability assessment overall IQ estimate. Covariates were analyzed separately and selected according to the methods of J. L. Jacobson and Jacobson (1996) to control the influence of variables that co-occur with prenatal smoking without inappropriately reducing exposure-related variance. If the correlation of the covariate with both exposure status (nonexposed vs. tobacco exposed) and the NTA factor score differed from zero at the $p<.10$ level, the covariate was included in the models.

For Attention, mother's age at delivery, maternal education, and the maternal IQ estimate were retained for consideration as covariates through these methods. All three candidate covariates were added to the baseline model, and a backwards stepwise procedure was used to determine which among them was to be retained in the final model. Mother's age was removed first from the model, $t(292)=0.12, p>.90$, followed by education, $t(291)=0.58, p>.55$. The remaining covariate - mothers' IQ estimate $-t(291)=3.33, p=.001$, was retained. None of the aforementioned covariates met the criteria for model inclusion for either Irritable Reactivity or Stress Dysregulation.

\section{Results}

Physical growth indices at birth as a function of exposure group status are shown in Table 3. Tobacco-exposed and nonexposed groups did not differ in birth weight, $t(301) \ldots 0.15$, $p_{-} .88$; head circumference, $t(299)=0.70, p>.48$; or length, $t(299)=0.16, p>87$. Within the exposed neonates, there were no differences in these physical growth indices in those born to women who quit during the first or second trimester (QUIT) and those whose smoking persisted throughout pregnancy (PERSIST; all $p \mathrm{~s}>.47$ ). Table 6 contains the results of regression models with the self-reported smoking and biospecimen predictors. Despite the lack of overall exposure group differences in birth weight, a dose- response relation was evident. Each additional cigarette smoked in the third trimester as reported by the mother was associated with an 11.55-g decrement in birth weight. A similar trend was observed for the 
number of cigarettes reported for the second trimester. The average number of cigarettes smoked per day in the week prior to both the 28- and 40-week interviews was associated with a respective birth weight decrement of 11.56 and $14.55 \mathrm{~g}$, respectively. Furthermore, cotinine in maternal urine at both the 16and 40- week interviews predicted birth weight, with a respective difference of -17.24 and -46.78 per $100 \mathrm{ng} / \mathrm{ml}$ cotinine. For body length, a similar dose-response pattern was evident, where the maternal urine cotinine levels at 16 and 40 weeks predicted decrements in body length at birth. Marginal trends were observed for the maternal urinary cotinine values at the 16-, 28-, and 40-week interviews. The magnitude of these effects was similar. Neither self-reported smoking nor biospecimen results predicted head circumference.

The estimated intercept and linear growth (if applicable) parameter values associated with the exposure predictors for the hierarchical growth models for the Irritable Reactivity, Attention, and Stress Dysregulation factor scores are presented in Table 7. Tobacco-exposed and nonexposed neonates differed in Attention factor score obtained shortly after birth and in the rate of growth. The pattern of Attention growth is shown in Figure 1a. Tobacco-exposed neonates had, on average, lower Attention scores by 0.32 at two days after birth than did nonexposed neonates, $t(765)=-3.23, p<0.01$. The significantly higher rate of growth $(\gamma=0.10)$ evidenced among tobacco-exposed neonates, $t(609)=2.88, p<.01$, resulted in a diminishing difference in Attention score means between the two groups at the 2-week time point of $0.14, t(299)=-2.01, p$ $<.05$, and comparable Attention scores between the groups at the 4 -week assessment, $t(692)=0.60, p>.55$.

Among tobacco-exposed neonates, the PERSIST and QUIT groups demonstrated different Attention factor scores shortly after birth and different rates of growth of these scores. The PERSIST group had, on average, lower Attention scores by 0.40 at two days after birth as compared with nonexposed neonates, $t(762)=-3.266, p<0.01$, and the difference of 0.24 between the QUIT and nonexposed groups was also significant, $t(766)=-1.98, p<.05$. The significantly higher rate of growth $(\gamma=0.126)$ evidenced among PERSIST neonates, $t(605)=2.94$, $p<.01$, resulted in a diminishing difference in Attention score means of 0.175 between the PERSIST and nonexposed groups at age 2 weeks, $t(298)=-1.98, p<.05$, and comparable Attention scores between the groups at the 4-week evaluation, $t(699)$ $=0.67, p>.50$. The QUIT group demonstrated a higher, but nonsignificant, rate of growth $(\gamma=0.072), t(609)=1.71, p>.08$ compared with the nonexposed group. Growth trajectories are shown in Figure 1b.

Self-reported average number of cigarettes smoked per day during the first trimester was related to the pattern of Attention growth in a dose-dependent fashion, with each cigarette smoked associated with a 0.034-reduction in Attention score at 0.2 weeks, $t(775)=-3.22, p<.01$, and with a faster rate of change of 0.012 in Attention score, $t(606)=3.15, p<$ .01 , across the neonatal period. A similar pattern was observed for self-reported smoking during the second trimester and the average number of cigarettes smoked per day reported in the week prior to the 28-week interview, with each cigarette smoked associated with a 0.047 and a 0.042 reduction, respectively, in Attention score at 0.2 weeks, $t(779)=$ $-4.03, p<.0001, t(784)=-3.72, p<.001$, and with a faster rate of Attention score change of 0.014 and $0.011, t(607)=3.36, p<$
$.0001, t(602)=2.69, p<.006$, across the neonatal period. Average self-reported smoking during the third trimester and in the week prior to the 40 -week interview also was related negatively to the Attention factor score, where each reported cigarette smoked per day was related to a 0.045 and 0.044 Attention score reduction, respectively, at 0.2 weeks, $t(782)=$ $-3.74, p<.001$, and $t(771)=-3.43, p<.001$, and was also associated with a 0.012 and 0.011 higher rate of change in Attention score, $t(608)=2.94, p<.01 ; t(600)=2.45, p<.02$. Cotinine levels in maternal urine collected at 28 weeks and at delivery were related to the pattern of growth in Attention scores such that greater assayed cotinine levels were associated with a reduction in Attention scores of 0.023 and 0.087 at 0.2 weeks, respectively, $t(771)=-2.00, p<.05, t(737)=-2.35, p<.02$, and with a marginally faster rate of change of 0.021 in Attention scores $(\gamma=0.021), t(579)=1.69, p<.10$. At 2 weeks of age, neonatal Attention scores were related negatively to average self-reported smoking during the second, $t(305)=-2.74, p<$ .01 , and third, $t(306)=-2.71, p<.01$, trimesters and smoking in the week prior to the 28-week, $t(305)=-2.93, p<.01$, and 40 -week, $t(304)=-2.71, p<.01$, interviews and was associated marginally with self-reported smoking in the first trimester, $t(307)=-1.78, p<.10$, and with maternal urine cotinine level at delivery, $t(291)=-1.89, p<.10$. All self-reported smoking and cotinine levels were not related to Attention score level at neonates' 4 weeks of age ( $p$ s > .30).

The group-related pattern of Irritable Reactivity growth is shown in Figure 1a. Unlike Attention, growth patterns did not differ significantly by exposure group classification at 0.2 weeks, $t(831)=0.36, p>.72$, or 2 weeks, $t(752)=1.52, p>$ .12. The tobacco-exposed group was consistently more irritable (difference in intercepts between tobacco-exposed and nonexposed groups of 0.039) across the neonatal period and reached marginal significance at 4 weeks of age $(\gamma=0.158)$, $t(684)=1.67, p<.10$. Similarly, no differences were noted between the nonexposed group and either of the exposure cessation groups: QUIT, $t(827)=0.86, p>.39$, or PERSIST, $t(832)$ $=-0.33, p>.74$, at 0.2 weeks, respectively. There were marginally significant Irritable Reactivity score differences between PERSIST and nonexposed participants at 2 weeks $(\gamma$ $=0.214), t(769)=1.67, p<.10$. Average self-reported smoking in each trimester or at each interview was not related to any Irritable Reactivity growth parameters, nor were maternal urine or meconium cotinine levels related to this factor at any time point.

Like Irritable Reactivity, Stress Dysregulation scores did not differ by exposure group classification, $t(841)=-0.26, p>$ .79 , nor were there any differences between the nonexposed group and either the QUIT or the PERSIST group, $t(836)=$ $-0.61, p>.54$, and $t(841)=0.13, p>.89$, respectively. For Stress Dysregulation, the variables of self-reported smoking at each interview, cotinine levels in maternal urine, and cotinine levels in neonatal meconium were unrelated to growth in Stress Dysregulation scores or to Stress Dysregulation scores at 0.2, 2 , or 4 weeks of age. Self-reported smoking during the first trimester was related marginally to quadratic growth $(\gamma=$ $-0.005), t(665)=-1.79, p<.08$, but not to Stress Dysregulation scores at any age, and average self-reported smoking in second and third trimesters was not related to any Stress Dysregulation growth parameters over the course of neonates' first month of life. 


\section{Discussion}

The impact of prenatal tobacco exposure on the early development of emergent self-regulatory processes and on physical growth at birth was assessed with a prospective design, indexing exposure through self-report and bioassays collected at several time points during pregnancy. Neonatal self-regulatory behaviors for modulating attention, irritability, and response to stressors were assessed three times in the first month of life and empirically parsed into meaningful constructs, enabling characterization of the dynamic impact of prenatal tobacco exposure on the trajectories of change in light of substantial growth and instability in this very early period (Korner, Kraemer, Reade, Forrest, \& Dimiceli, 1987). This finegrained analytic strategy enabled a number of new insights into the effects of exposure on the very early development of self-regulatory behaviors in several domains.

Although the prevalence, amount, and persistence of smoking in pregnant women today differs from that in previous decades, the oft-reported continuous dose-response relation between pregnancy smoking and birth weight was evident here. Heavier and more persistent smoking across pregnancy impacted birth weight and body length deleteriously. Self-reported second- and third-trimester smoking, self-reported smoking at the 28- and 40-week interviews, and cotinine in maternal urine at 16 and 40 weeks, predicted birth-weight decrements. The magnitude of the exposure effect on birth-weight effect was largest for these third-trimester smoking predictors compared with those measured earlier in pregnancy. Maternal urinary cotinine at delivery also was associated with significant body length decrements. Marginal trends were observed for maternal urine cotinine levels at the 16-, 28-, and 40-week interviews. In contrast to these dose-response relations, the lack of exposure group differences in these indices of physical growth at birth is likely a consequence of lower amount of tobacco exposure overall compared with cohorts ascertained in the 1970s and 1980s, the sample selection methods to minimize other influences and exposures, and the greater sensitivity of continuous measures of exposure in comparison with gross grouping. Neither exposure-group-level nor dose-response differences in head circumference were evident, suggesting that the protective, brain-growth-sparing mechanism was not affected by prenatal tobacco exposure, unlike what has been observed in prenatally cocaine exposed neonates (Eyler, Behnke, Conlon, Woods, \& Wobie, 1998).

Importantly, the pattern of development of attention skills differed among tobacco-exposed and nonexposed neonates across the first month of life. Consistent with the stated hypotheses, tobacco-exposed neonates showed less orientation and attentive tracking behaviors to auditory and visual stimuli. Interestingly, exposure group differences were not constant over the first month of life. Differences were most evident on the Attention factor scores from the assessment conducted shortly after birth and remained apparent at 2 weeks of age. By 4 weeks of age, however, Attention scores were comparable between the two groups, contrary to prediction. This average trajectory is consistent with a general pattern of developmental catch-up, where the initial reduced level of performance in tobacco-exposed neonates was accompanied by a more rapid rate of development, resulting in comparable skills at the end of the observation period. Furthermore, attention skills scores were lower shortly after birth in tobacco-exposed neonates whose mothers smoked more and more persistently across pregnancy compared with those who quit smoking during or before the second trimester. Of note too is the relatively modest change in Attention skills in nonexposed neonates relative to the fairly steep rate of change for tobacco-exposed neonates, which again was greater in those who smoked more and more persistently in pregnancy.

Clearly, early in the neonatal period, attention skills differed in tobacco-exposed neonates relative to their nonexposed peers. What is unclear is whether this difference reflects an effect of withdrawal or is a unique exposure-related developmental vulnerability in this period of rapid change. The differences in attention observed shortly after birth are consistent with withdrawal effects, reflecting the residual rebound impact of cessation of nicotine exposure that occurs as a consequence of birth. This interpretation is consistent with earlier findings where exposure also was measured with self-report (e.g., Fried et al., 1987; S. W. Jacobson, 1984; G. A. Richardson et al., 1989; Saxton, 1978; Streissguth, Sampson, Barr, Bookstein, \& Carmichael, 1994). These findings are also consistent with those from a more recent study that included bioassays of exposure and was specifically designed to examine withdrawal in the first days of life (Godding et al., 2004). The dose-response relation observed in the present between selfreported maternal smoking in the third trimester and at the delivery interview, as well as cotinine levels in maternal urine at delivery and in neonatal meconium, and the level of attention behavior observed shortly after birth support the withdrawal interpretation.

Withdrawal effects from progressive nicotine clearing also might contribute to the substantive differences observed in Attention scores that persisted at 2 weeks of age. The difference in Attention scores between tobacco-exposed and nonexposed neonates was substantially smaller (about half in magnitude) at 2 weeks of age compared with shortly after birth. Self-reported smoking in the third trimester and at the 40-week interview, as well as cotinine levels in maternal urine at delivery, predicted the differences of Attention scores between tobaccoexposed and nonexposed infants at 2 weeks of age. However, cotinine levels in neonatal meconium were not related to attention behaviors at 2 weeks of age, which would have been expected if the exposure group differences were due to receding withdrawal effects.

Typically, 2 weeks of age is considered beyond the window when acute withdrawal effects are observed (Stroud, Paster, Papandonatos, et al., 2009). Unlike Godding et al. (2004), women in the present sample reported smoking substantially fewer cigarettes per day. The decreased number of cigarettes per day across pregnancy results in a much lower dose of nicotine to be cleared after birth and thereby might decrease the likelihood and severity of withdrawal effects shortly after birth and certainly 2 weeks later. In the present study, neonates whose mothers quit smoking during pregnancy showed poorer attention and orientation skills shortly after birth compared with those who were nonexposed, which also is not consistent with withdrawal effects. Furthermore, the amount of smoking reported in the first and second trimesters, as well as in the week prior to the 28-week interview, predicted attention skills at 2 weeks of age, earlier in pregnancy than would be a consequence of nicotine clearing. However, the general consistency is that smoking across pregnancy, and the resultant substantive correlations between smoking indicators mea- 
sured at different points during pregnancy, makes it difficult to attribute independent effects on neurobehavior at each age. The observed differences in attention early in the neonatal period, however, also are not likely to be due to secondhand tobacco exposure, as secondhand smoke exposure was low in the neonatal period, confirmed by the low cotinine levels in neonate urine and the much smaller relation to prenatal smoking amounts of our present study.

Although exposure-group-related differences in attention were expected at 4 weeks of age, the average trajectories did not differ between exposure groups at the end of the neonatal period. Neither self-reported smoking nor cotinine levels measured in biospecimens were related to exposure group differences in Attention scores at 4 weeks of age, consistent with results obtained by Yolton et al. (2009). The pattern of skill growth for tobacco-exposed neonates was consistent with initial deficits followed by subsequent "recovery," where at 4 weeks of age, all neonates showed comparable attention skills. In this period of rapid developmental growth in attention skills for all neonates, tobacco-exposed neonates show early deficits, as well as faster growth rates, both of which were related to the degree of exposure. The longitudinal design used here disentangled the age-specific exposure effects in the context of the developmental trajectory of skill development.

Also contrary to hypothesis, exposure-group-level (tobacco exposed vs. nonexposed) differences in the Irritable Reactivity factor scores shortly after birth were not significant; nor were there exposure group effects on linear or quadratic growth rates. These findings contrast with those from other studies that used both self-report (Fried \& Makin, 1987; S. W. Jacobson, 1984; Nugent, Lester, Greene, \& Wieczorek-Deering, 1996; Picone et al., 1982; Schuetze \& Eiden, 2007) and bioassays (Godding et al., 2004; Law et al., 2003; Mansi et al., 2007; Stroud, Paster, Goodwin, et al., 2009) to index prenatal tobacco exposure. What is of interest here is the impact on the developmental pattern, where the consistent exposure-related differences in Irritable Reactivity scores between groups were visually evident at each age and persistent across the neonatal period. The magnitude of the estimated difference in irritable reactivity between tobacco-exposed and nonexposed neonates was progressively greater across time points, where at 4 weeks, exposure groups differed marginally. A second look at the individual trajectories of Irritable Reactivity scores across age suggested a high degree of between-subjects variability in exposure-related impacts on Irritable Reactivity scores that is superimposed upon a general neonatal increase in irritable reactivity across the neonatal period. Person-centered methods (e.g., Espy, Fang, Charak, Minich \& Taylor, 2009) might be applied fruitfully to identify specific groups of neonates with discrepant neonatal developmental patterns related to exposure. Birth is a stressful, energy-demanding event from which newborns recover through initial high levels of sleep and low irritability (Korner, 1996; Korner, Brown, Reade, \& Stevenson, 1988). Because the Irritable Reactivity factor is composed of items that score irritable reactivity to daily living activities to handling, physical maneuvers, auditory and visual stimulation-exposure-related irritability would be expected to be observed routinely and persistently, at least for a subset who are most vulnerable. Given the importance of irritability to solicit caregiving, these early, subtle differences perhaps set the stage for the ensuing deviations in maternal-infant behavior that have been observed (Schuetze \& Eiden, 2006, 2007) and may be an early precursor to later deviations in emotional dysregulatory behavior (Brook et al., 2000; Wakschlag, Leventhal, Pine, Pickett, \& Carter, 2006).

Although the self-reported average first-trimester smoking was related marginally to a decrease in the rate of deceleration in Stressor Dysregulation factor scores, none of the other exposure variables - self-report or biospecimen data-predicted differences in the rates of change in, or in the age-specific level of, the dysregulation response to midlevel stressors. Dysregulation behaviors in response to a relatively acute, substantial stressor might be more resilient to the deleterious impact of prenatal tobacco exposure, given their deeply rooted, evolution-selected, adaptive role in signaling immediate discomfort and distress. It is important to note, however, that the Irritable Reactivity and Stress Dysregulation factor scores were related substantively and, thus, teasing apart the isolated impact of exposure on these two dimensions is not a simple endeavor. Because tobacco-exposed neonates showed more irritability in response to routine handling as shown by the Irritable Reactivity factor score difference, the introduction of a stressful stimulus (e.g., cold disc) might not have provoked as much of an increase in negative emotionality as a result of natural constraints in the neonatal behavioral repertoire, somewhat akin to a ceiling effect. Including stress biomarkers, such as cortisol or heart-rate measurements, might reveal latent physiologic differences that could help disentangle these two dimensions, as these methods have been successful in revealed exposurerelated differences (e.g., Franco, Chabanski, Szilwowski, Dramaix, \& Kahn, 2000; Schuetze \& Eiden, 2006).

Sampling methods of this study deserve particular comment, particularly in light of the decadal changes in smoking behavior, as a contributor to the obtained pattern of findings. First, women were recruited prospectively in the first trimester, and thus it was impossible to balance selection on persistence of smoking throughout pregnancy. Second, our goal was to minimize extraneous influences other than smoking; thus, nonsmoking women were selected specifically to be more comparable demographically to those who smoked, which certainly resulted in exposure groups that were more similar (although not completely so) than is typically found in community-based samples. Consistent with minimizing extraneous influences and with our interests in the neurobiologic effects of nicotine on the nervous system, our goal was to minimize the impact of other exposures, and thus women who reported illegal drug use at screening or at interview or who tested positive in biospecimens, as well as those with known heavy alcohol use, were not included in the report here. The benefit of this sampling design is its highlighting of the prenatal tobacco exposure effects among the background of risks. The downside, however, is that there were fewer heavier and more persistent smokers in the present study, as higher alcohol and other drug use is substantially more common in women who smoke heavily during pregnancy. These sampling differences must be evaluated carefully in interpreting the pattern of findings across studies.

One strength of this effort is the longitudinal design that permitted characterization of the impact of prenatal tobacco exposure on the development of regulatory skills across the first month of life. These findings serve to link those from other cross-sectional studies that have focused on withdrawal effects, regulatory behavior shortly after birth, and the longerterm, residual impacts of later exposure at the end of neonatal 
period. The longitudinal measurement and growth modeling strategy takes advantage of the increased reliability of change to describe developmental processes and deviations (Rogosa \& Willett, 1985). The average trajectory was consistent with a catch-up pattern for attention skills, consistent with self-righting resilience in development, at least in this sample with relatively low amounts of smoking and less confounding by other exposures. The observed trajectory, however, is simply a mathematical average, and is superimposed on substantial individual variation. Of course, the effects observed here in the neonatal period are only the first step in establishing the dynamic impact of prenatal tobacco exposure on the developing nervous system that supports regulatory processes within the broader context of parenting and the social environment that also interactively shapes development as it unfolds. Whether the initial developmental patterns observed in the neonatal period are related to disturbances in later attention and emotion regulation behaviors is an important future question, as these more basic neonatal skills are integrated into the increasingly complex behavior repertoire of the developing infant and child that are expressed dynamically in varying social contexts.

\section{References}

Azam, L., Chen, Y., \& Leslie, F. M. (2007). Developmental regulation of nicotinic acetylcholine receptors within midbrain dopamine neurons. Neuroscience, 144, 1347-1360.

Baghurst, P. A., Tong, S. L., Woodward, A., \& McMichael, A. J. (1992). Effects of maternal smoking upon neuropsychological development in early childhood: Importance of taking account of social and environmental factors. Paediatric and Perinatal Epidemiology, 6, 403-415.

Bard, K. A., Coles, C. D., Platzman, K. A., \& Lynch, M. E. (2000). The effects of prenatal drug exposure, term status, and caregiving on arousal and arousal modulation in 8-week-old infants. Developmental Psychobiology, 36, 194-212.

Bennett, D. S., Mohamed, F. B., Carmody, D. P., Bendersky, M., Patel, S., Khorrami, M., \& Lewis, M. (2009). Response inhibition among early adolescents prenatally exposed to tobacco: An fMRI study. Neurotoxicology and Teratology, 31, 283-290.

Brook, J., Brook, D., \& Whiteman, M. (2000). The influence of maternal smoking during pregnancy on the toddler's negativity. Archives of Pediatric and Adolescent Medicine, 154, 381-385.

Centers for Disease Control. (2008, August). Alcohol terms. Retrieved from http://www.cdc.gov/alcohol/terms. htm\# excessive

Chen, H., Parker, S. L., Matta, S. G., \& Sharp, B. M. (2005). Gestational nicotine exposure reduces nicotinic cholinergic receptor (nAChR) expression in dopaminergic brain regions of adolescent rats. European Journal of Neuroscience, 22, 380-388.

Conners, C. K., Erhardt, D., \& Sparrow, E. P. (1998). CAARS - Selfreport: Short Version (CAARS-S:S). North Tonawanda, NY: Multi- Health Systems.

Conter, V., Cortinovis, L., Rogari, P., \& Riva, L. (1995). Weight growth in infants born to mothers who smoked during pregnancy. British Medical Journal, 310, 768-776.

Day, N., Cornelius, M., Goldschmidt, L., Richardson, G., Robles, N., \& Taylor, P. (1992). The effects of prenatal tobacco and marijuana use on offspring growth from birth through 3 years of age. Neurotoxicology and Teratology, 14, 407-414.
Day, N. L., Richardson, G. A., Goldschmidt, L., \& Cornelius, M. D. (2000). Effects of prenatal tobacco exposure on preschoolers' behavior. Journal of Developmental and Behavioral Pediatrics, 21, 180-188.

Derogatis, L. R. (1975). Brief Symptom Inventory. Baltimore, MD: Clinical Psychometric Research.

D'Onofrio, B., Van Hulle, C., Waldman, I., Rodgers, J., Rathouz, P., \& Lahey, B. (2007). Causal inferences regarding prenatal alcohol exposure and childhood externalizing problems. Archives of General Psychiatry, 64, 1296-1304.

Emde, R. N., \& Buchsbaum, H. K. (1989). Toward a psychoanalytic theory of affect: II. Emotional development and signaling in infancy. In S. I. Greenspan \& G. H. Pollack (Eds.), The course of life: Infancy (pp. 193-227). Madison, CT: International Universities Press.

England, L. J., Grauman, A., Qian, C., Wilkins, D. G., Schisterman, E. F., Yu, K. F., \& Levine, R. J. (2007). Misclassification of maternal smoking status and its effects on an epidemiologic study of pregnancy outcomes. Nicotine Tobacco Research, 9, 1005-1013.

Espy, K. A., Fang, H., Charak, D., Minich, N., \& Taylor, H. G. (2009). Growth mixture modeling of academic achievement in children of varying birth weight risk. Neuropsychology, 23, 460-474.

Espy, K. A., Riese, M. L., \& Francis, D. J. (1997). Neurobehavior in preterm neonates exposed to cocaine, alcohol, and tobacco. Infant Behavior and Development, 20, 297-309.

Eyler, F. D., \& Behnke, M. (1999). Early development of infants exposed to drugs prenatally. Clinical Perinatology, 26, 107-150.

Eyler, F. D., Behnke, M., Conlon, M., Woods, N. S., \& Wobie, K. (1998). Birth outcome from a prospective, matched study of prenatal crack/ cocaine use: I. Interactive and dose effects on health and growth. Pediatrics, 101, 229-237.

Franco, P., Chabanski, S., Szilwowski, H., Dramaix, M., \& Kahn, A. (2000). Influence of maternal smoking on autonomic nervous system in healthy infants. Pediatric Research, 47, 215-220.

Fried, P. A., \& Makin, J. E. (1987). Neonatal behavioural correlates of prenatal exposure to marijuana, cigarettes and alcohol in a low risk population. Journal of Neurotoxicology and Teratology, 9, 1-7.

Fried, P. A., \& Watkinson, B. (2001). Differential effects on facets of attention in adolescents prenatally exposed to cigarettes and marihuana. Journal of Neurotoxicology and Teratology, 23, 421-430.

Fried, P. A., Watkinson, B., Dillon, R. F., \& Dulberg, C. S. (1987). Neonatal neurological status in a low-risk population after prenatal exposure to cigarettes, marijuana, and alcohol. Journal of Developmental \& Behavioral Pediatrics, 8, 318-326.

Fried, P. A., Watkinson, B., \& Gray, R. (1992). A follow-up study of attentional behavior in 6-year-old children exposed prenatally to marihuana, cigarettes, and alcohol. Journal of Neurotoxicology and Teratology, 14, 299.

Godding, V., Bonnier, C., Fiasse, L., Michel, M., Longueville, E., Lebecque, P., \& Galanti, L. (2004). Does in utero exposure to heavy maternal smoking induce nicotine withdrawal symptoms in neonates? Pediatric Research, 55, 645-651.

Goldman, P. S. (1974). Plasticity of function in the CNS. In D. G. Stein, J. J. Rosen, \& N. Butters (Eds.), Plasticity and recovery of function in the central nervous system (pp. 149-174). London: Academic Press.

Gorsuch, R. L. (1983). Factor analysis. (2nd ed.). Hillsdale, NJ: Erlbaum.

Hagino, N., \& Lee, J. (1985). Effect of maternal nicotine on the development of sites for $\left[{ }^{3} \mathrm{H}\right]$ nicotine binding in the fetal brain. International Journal of Developmental Neuroscience, 3, 567-571. 
Hardy, J., \& Mellits, E. (1972). Does maternal smoking during pregnancy have a long-term effect on the child? Lancet, 2, 1332-1336.

Huizink, A. C., \& Mulder, E. J. (2006). Maternal smoking, drinking or cannabis use during pregnancy and neurobehavioral and cognitive functioning in human offspring. Neuroscience and Biobehavioral Reviews, 30, 24-41.

Jacobsen, L., Slotkin, T., Westerveld, M., Mencl, W., \& Pugh, K. R. (2006). Visuospatial memory deficits emerging during nicotine withdrawal in adolescents with prenatal exposure to active maternal smoking. Neuropsychopharmacology, 31, 1550-1561.

Jacobson, J. L., \& Jacobson, S. W. (1996). Methodological considerations in behavioral toxicology in infants and children. Developmental Psychology, 32, 390-403.

Jacobson, S. W. (1984). Neonatal correlates of prenatal exposure to smoking, caffeine, and alcohol. Infant Behavior and Development, 7, 253- 265.

Johnson, C. H., Vicary, J. R., Heist, C. L., \& Corneal, D. A. (2001). Moderate alcohol and tobacco use during pregnancy and child behavior outcomes. Journal of Primary Prevention, 21, 367-379.

Kelmanson, I. A., Erman, L. V., \& Litvina, S. V. (2002). Maternal smoking during pregnancy and behavioural characteristics in 2-4-month-old infants. Klinische Pädiatrie, 214, 359-364.

Kopp, C. B. (1982). Antecedents of self-regulation: A developmental perspective. Developmental Psychology, 18, 199-214.

Koren, G. (1993). Cocaine and the human fetus: The concept of teratophilia. Journal of Neurotoxicology and Teratology, 15, 301-304; discussion, 311-302.

Korner, A. F. (1996). Reliable individual differences in preterm infants' excitation management. Child Development, 67, 1793-1805.

Korner, A. F., Brown, B. W., Dimiceli, S., \& Forrest, T. (1989). Stable individual differences in developmentally changing preterm infants: A replicated study. Child Development, 60, 502-513.

Korner, A. F., Brown, B. W., Reade, E. P., \& Stevenson, D. K. (1988). State behavior of preterm infants as a function of development, individual and sex differences. Infant Behavior and Development, 11, 111-124.

Korner, A. F., Kraemer, H. C., Reade, E. P., Forrest, T., \& Dimiceli, S. (1987). A methodological approach to developing an assessment procedure for testing the neurobehavioral maturity of preterm infants. Child Development, 58, 1478-1487.

Kotimaa, A. J., Moilanen, I., Taanila, A., Ebeling, H., Smalley, S. L., \& Järvelin, S. R. (2003). Maternal smoking and hyperactivity in 8-year-old children. Journal of the American Academy of Child and Adolescent Psychiatry, 42, 826-833.

Landmesser, L. (1994). Axonal outgrowth and pathfinding. Progress in Brain Research, 103, 67-73.

Law, K., Stroud, L., LaGasse, L., Niaura, R., Liu, J., \& Lester, B. (2003). Smoking during pregnancy and newborn neurobehavior. Pediatrics, 111, 1318-1323.

Leech, S. L., Richardson, G. A., Goldschmidt, L., \& Day, N. L. (1999). Prenatal substance exposure: Effects on attention and impulsivity of 6-year-olds. Neurotoxicology and Teratology, 21, 109-118.

Levin, E. D., \& Slotkin, T. A. (1998). Developmental neurotoxicity of nicotine. San Diego: Academic Press.

Lichtensteiger, W., Hefti, F., Felix, D., Huwyler, T., Melamed, E., \& Schlumpf, M. (1982). Stimulation of nigrostriatal dopamine neurones by nicotine. Neuropharmacology, 21, 963-968.

Linnet, K. M., Dalsgaard, S., Obel, C., Wisborg, K., Henriksen, T.
B., Rodriguez, A., \& Jarvelin, M. R. (2003). Maternal lifestyle factors in pregnancy risk of attention deficit hyperactivity disorder and associated behaviors: Review of the current evidence. American Journal of Psychiatry, 160, 1028-1040.

Little, R. J. A., \& Rubin, D. B. (2002). Statistical analysis with missing data. New York: Wiley.

Mansi, G., Raimondi, F., Pichini, S., Capasso, L., Sarno, M., Zuccaro, P., \& Paludetto, R. (2007). Neonatal urinary cotinine correlates with behavioral alterations in newborns prenatally exposed to tobacco smoke. Pediatric Research, 61, 257-261.

Matheny, A. P., Riese, M. L., \& Wilson, R. S. (1985). Rudiments of infant temperament: Newborn to 9 months. Developmental Psychology, 21, 486-494.

Maughan, B., Taylor, A., Caspi, A., \& Moffitt, T. E. (2004). Prenatal smoking and early childhood conduct problems: Testing genetic and environmental explanations of the association. Archives of General Psychiatry, 61, 836-843.

McFarland, B. J., Seidler, F. J., \& Slotkin, T. A. (1991). Inhibition of DNA synthesis in neonatal rat brain regions caused by acute nicotine administration. Developmental Brain Research, 58, 223-229.

Muneoka, K., Ogawa, T., Kamei, K., Muraoka, S., Tomiyoshi, R., Mimura, Y., \& Takigawa, M. (1997). Prenatal nicotine exposure affects the development of the central serotonergic system as well as the dopaminergic system in rat offspring: Involvement of route of drug administrations. Developmental Brain Research, 102, 117-126.

Navarro, H. A., Seidler, F. J., Whitmore, W. L., \& Slotkin, T. A. (1988). Prenatal exposure to nicotine via maternal infusions: Effects on development of catecholamine systems. Journal of Pharmacology and Experimental Therapeutics, 244, 940-944.

Nigg, J. T., \& Breslau, N. (2007). Prenatal smoking exposure, low birth weight, and disruptive behavior disorders. Journal of the American Academy of Child and Adolescent Psychiatry, 46, 362-369.

Nugent, J. K., Lester, B. M., Greene, S. M., \& Wieczorek-Deering, D. (1996). The effects of maternal alcohol consumption and cigarette smoking during pregnancy on acoustic cry analysis. Child Development, 67, 1806-1815.

Office of Applied Studies. (2005). Results from the 2004 National Survey on Drug Use and Health: National findings (DHHS Publication No. SMA 05-4062, NSDUH Series H-28). Rockville, MD: Substance Abuse and Mental Health Services Administration.

Picone, T. A., Allen, L. H., Olsen, P. N., \& Ferris, M. E. (1982). Pregnancy outcome in North American women: II. Effects of diet, cigarette smoking, stress, and weight gain on placentas, and on neonatal physical and behavioral characteristics. American Journal of Clinical Nutrition, 36, 1214-1224.

Rantakallio, P. (1983). A follow-up study to the age of 14 of children whose mothers smoked during pregnancy. Acta Paediatrica Scandinavica, 72, 747-753.

Richardson, G. A., Day, N. L., \& Taylor, P. M. (1989). The effect of prenatal alcohol, marijuana, and tobacco exposure on neonatal behavior. Infant Behavior and Development, 12, 199-209.

Richardson, S. A., \& Tizabi, Y. (1994). Hyperactivity in the offspring of nicotine-treated rats: Role of the mesolimbic and nigrostriatal dopaminergic pathways. Pharmacology, Biochemistry and Behavior, 47, 331- 337.

Riese, M. L. (1982). Procedures and norms for assessing behavioral patterns in full-term and stable pre-term neonates. JSAS Catalog of Selected Documents in Psychology, 12, 6.

Riese, M. L. (1983). Assessment of behavioral patterns in neonates. Infant Behavior and Development, 6, 241-246. 
Riese, M. L. (1986). Implications of sex differences in neonatal temperament for early risk and developmental/environmental interactions. Journal of Genetic Psychology, 147, 507-513.

Riese, M. L. (1987). Temperament stability between the neonatal period and 24 months. Developmental Psychology, 23, 216-222.

Riese, M. L. (1995). Mothers' ratings of infant temperament: Relation to neonatal latency to soothe by pacifier. Journal of Genetic Psychology, 156, 23-31.

Riese, M. L., Wilson, R. S., \& Matheny, A. P., Jr. (1985). Multimethod assessment of temperament in twins: Birth to six months. Acta Geneticae Medicae et Gemellologiae, 34, 15-31.

Rodriguez, A., \& Bohlin, G. (2005). Are maternal smoking and stress during pregnancy related to ADHD symptoms in children? Journal of Child Psychology and Psychiatry, 46, 246-254.

Rogosa, D., \& Willett, J. (1985). Understanding the correlates of change by modeling individual differences in growth. Psychometrika, 50, 203-228.

Roza, S. J., Verburg, B. O., Jaddoe, V. W., Hofman, A., Mackenbach, J. P., \& Tiemeier, H. (2007). Effects of maternal smoking in pregnancy on prenatal brain development. The Generation R Study. European Journal of Neuroscience, 25, 611-617.

Saxton, D. W. (1978). The behaviour of infants whose mothers smoke in pregnancy. Early Human Development, 2, 363-369.

Schuetze, P., \& Eiden, R. (2006). The association between maternal smoking and secondhand exposure and autonomic functioning at 2-4 weeks of age. Infant Behavior and Development, 29, 32-43.

Schuetze, P., \& Eiden, R. (2007). The association between prenatal exposure to cigarettes and infant and maternal negative affect. Infant Behavior and Development, 30, 387-398.

Schuetze, P., Eiden, R., \& Dombkowski, L. (2006). The association between cigarette smoking during pregnancy and maternal behavior during the neonatal period. Infancy, 10, 267-288.

Seidler, F. J., Levin, E. D., Lappi, S. E., \& Slotkin, T. A. (1992). Fetal nicotine exposure ablates the ability of postnatal nicotine challenge to release norepinephrine from rat brain regions. Developmental Brain Research, 69, 288-291.

Slotkin, T. A. (1998a). Consensus on postnatal deficits: Comparability of human and animal findings. Annals of the New York Academy of Sciences, 846, 153-157.

Slotkin, T. A. (1998b). Fetal nicotine or cocaine exposure: Which one is worse? Journal of Pharmacology and Experimental Therapeutics, 285, 931-945.

Slotkin, T. A., Greer, N., Faust, J., Cho, H., \& Seidler, F. J. (1986). Effects of maternal nicotine injections on brain development in the rat: Ornithine decarboxylase activity, nucleic acids and proteins in discrete brain regions. Brain Research Bulletin, 17, 41-50.

Slotkin, T. A., Lappi, S. E., \& Seidler, F. J. (1995). Beta-adrenergic control of c-fos expression in fetal and neonatal rat tissues: Relationship to cell differentiation and teratogenesis. Toxicology and Applied Pharmacology, 133, 188-195.

Sobell, L. C., \& Sobell, M. B. (1992). Timeline follow-back: A technique for assessing self-reported alcohol consumption. In R. Z. Littenand \& J. P. Allen (Eds.), Measuring alcohol consumption: Psychosocial and biological methods (pp. 41-72). Totowa, NJ: Humana Press.
Streissguth, A. P., Sampson, P. D., Barr, H. M., Bookstein, F. L., \& Carmichael Olson, H. (1994). The effects of prenatal exposure to alcohol and tobacco: Contributions of the Seattle Longitudinal Prospective Study and implications for public policy. In H. L. Needleman \& D. Bellinger (Eds.), Prenatal exposure to toxicants: Developmental consequences (pp. 148-183). Baltimore, MD: John Hopkins University Press.

Stroud, L. R., Paster, R. L., Goodwin, M. S., Shenassa, E., Buka, S., Niaura, R., \& Lipsitt, L. P. (2009). Maternal smoking during pregnancy and neonatal behavior: A large-scale community study. Pediatrics, 123, 842-848.

Stroud, L. R., Paster, R. L., Papandonatos, G. D., Naura, R., Salisbury, A. L., Battle, C., \& Lester, B. (2009). Maternal smoking during pregnancy and newborn neurobehavior: Effects at 10 to 27 days. Journal of Pediatrics, 154, 4-5.

Szatmari, P., Saigal, S., Rosenbaum, P., Campbell, D., \& King, S. (1990). Psychiatric disorders at five years among children with birthweights <1000g: A regional perspective. Developmental Medicine and Child Neurology, 32, 954-962.

Thapar, A., Fowler, T., Rice, F., Scourfield, J., van den Bree, M., Thomas, H., \& Hay, D. (2003). Maternal smoking during pregnancy and attention deficit hyperactivity disorder symptoms in offspring. American Journal of Psychiatry, 160, 1985-1989.

Vik, T., Jacobsen, G., Vatten, L., \& Bakketeig, L. S. (1996). Pre- and post-natal growth in children whose mothers smoked during pregnancy. Early Human Development, 45, 245-255.

Wakschlag, L. S., \& Hans, S. L. (2002). Maternal smoking during pregnancy and conduct problems in high-risk youth: A developmental framework. Developmental Psychopathology, 14, 351-369.

Wakschlag, L. S., Leventhal, B. L., Pine, D. S., Pickett, K. E., \& Carter, A. S. (2006). Elucidating early mechanisms of developmental psychopathology: The case of prenatal smoking and disruptive behavior. Child Development, 77, 893-906.

Wakschlag, L. S., Pickett, K. E., Cook, E., Jr., Benowitz, N. L., \& Leventhal, B. L. (2002). Maternal smoking during pregnancy and severe antisocial behavior in offspring: A review. American Journal of Public Health, 92, 966-974.

Williams, G. M., O'Callaghan, M., Najman, J. M., Bor, W., Andersen, M. J., Richards, D., et al. (1998). Maternal cigarette smoking and child psychiatric morbidity: A longitudinal study. Pediatrics, 102, e11.

Willoughby, M., Greenberg, M., Blair, C., Stifter, C., \& Family Life Investigative Group. (2007). Neurobehavioral consequences of prenatal exposure to smoking at 6 to 8 months of age, Infancy, 12, 273-301.

Woodcock, R. W., McGrew, K. S., \& Mather, N. (2001). WoodcockJohnson III Tests of Cognitive Abilities: Brief Intellectual Ability. Itasca, IL: Riverside Publishing.

Yolton, K., Khoury, J., Xu, Y., Succop, P., Lanphear, B., Bernert, J. T., \& Lester, B. (2009). Low-level prenatal exposure to nicotine and infant neurobehavior. Neurotoxicology $\mathcal{E}$ Teratology, 31, 356-363. 